\title{
Assessment of Influence of Technological Parameters on Peat Extraction
}

\author{
Olga Puhova ${ }^{1}$, and Vladimir Lebedev ${ }^{1}$ \\ ${ }^{1}$ Tver State Technical University, A. Nikitin Street 22, 170026, Tver, Russia
}

\begin{abstract}
The article evaluates the weather and hydrological impact on geotechnology when fragmented peat is milled and dried at a peat deposit. The amount of moisture feeding the fragmented peat of a deposit was studied and was determined to depend on the ground water level. The influence of drainage on the water regime of a high-more peat deposit and that of weather conditions on ground water level fluctuations over time have been evaluated at production sites with an open drainage network. When a peat deposit is drained, under the action of gravitation (the pressure differential in the ground and a drain), ground water seeps into the drains and is transported along them, down-grade, to the collection network and diverted from the drained area. The processes of moisture movement at a peat deposit help evaluate and justify measures to improve its water-air regime which is used in the development of intensive draining methods for a peat deposit and the maintenance of the necessary water regime in peat deposits.
\end{abstract}

\section{Introduction}

The sustainable management of peat reserves determines the possible directions of using the peat resources of a specific peat deposit $[1-2,3]$. Natural conditions and their changes due to technological impacts on a deposit are taken into account in designing $[4-6,8]$ and managing [2, 7-10] peat mining enterprises.

Meteorological conditions (wind speed, air temperature and humidity) play an important role in geotechnology when fragmented peat is dried naturally. The technological process of fragmented peat extraction and drying must be linked to weather factors and the choice of an optimal depth of a fragmented peat layer. Currently, its constant depth is used for milling throughout the season. This results in the situation that on meteorologically good days the layer reaches the harvesting moisture content before the set time after which the peat becomes overdried. The milling of such peat gives a heavy dusting which leads to its losses and contamination of the surrounding area. As a result, less peat is extracted than it could be done under favorable meteorological conditions [3,11-14]. Weather conditions are underutilised. On the contrary, if the weather conditions are poor, the layer of fragmented peat does not have time to reach the harvesting moisture content before the end of the cycle, which leads to the underutilization of favourable drying conditions in milling peat deposits. The cycle is delayed and moved to the next day, the number of cycles is reduced and, therefore, the seasonal fees are reduced. The system of open canals in combination with closed drains can decrease the level of ground water and, thereby, decrease the moisture 
content of a peat deposit [15-17]. Open canals and drains are dug through according to certain schemes.

\section{Results}

The studies conducted on a high-moor peat deposit with a $20 \%$ decomposition degree evaluated two types of factors: meteorological (temperature, humidity, wind speed, cloudiness) and hydrological (ground water table, heat and mass transfer of moisture). The ground water located $50-60 \mathrm{~cm}$ below the surface of the deposit was not found to affect the drying of fragmented peat lying on the surface of a peat deposit (Fig. 1).

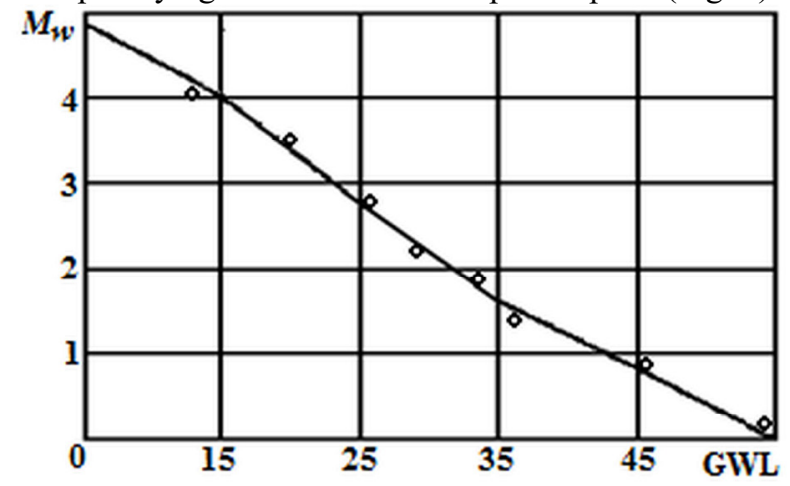

Fig. 1. The amount of moisture fed by a deposit fragmented peat.

In any type of drainage, under the action of gravitation (the pressure differential in the ground and a drain) ground water seeps into pipes (wells) or canals and is transported through them (down-grade or by other means) to the collection network and removed from the drained area (Fig.2).

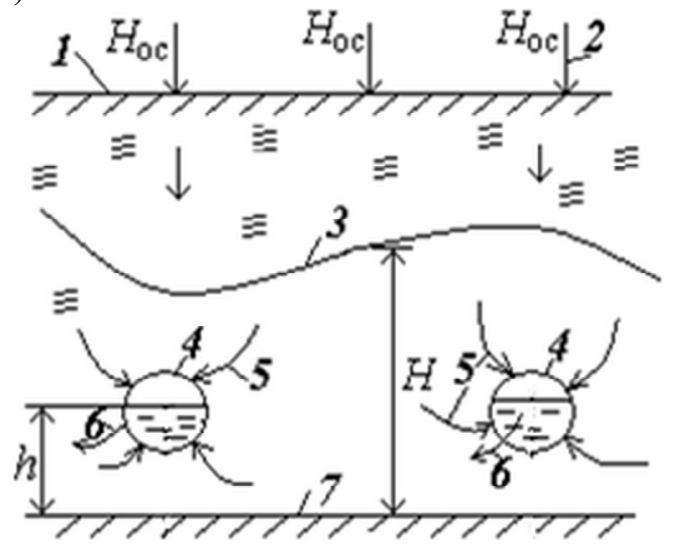

Fig. 2. Scheme of excess water drainage: 1 - a peat deposit surface; 2 - precipitation; 3 - ground water level; 4 - a drain; 5 - the direction of ground water movement (flow lines); 6 - the direction of drained water movement; 7 - aquiclude; $H$ - acting head

Deposit properties and boundary conditions, namely the rate of incoming infiltration moisture, the design and location of drains, hydrogeological conditions, determine the position of the underground water level [18]. The decrease in the underground water level caused by the action of drains (both an open drainage network and drainage) directly affects the overlying zone maintaining the necessary water-air regime in it. 
The moisture movement in the zone below the underground water level can be considered, to a first approximation, as a steady stationary flow. An important distinctive feature of the zone located below the underground water level is the capability of any cavity to pass water with little resistance.

When peat extraction is organised at production sites with an open drainage network, the drainage improves drying conditions as the underground water level decreases (Fig. 3) and precipitation increases it slightly. In addition, when intense precipitation finishes, the underground water level decreases shortly and reaches the level not affecting the drying. The same occurs in the extraction of sapropel buried under a layer of peat deposits.

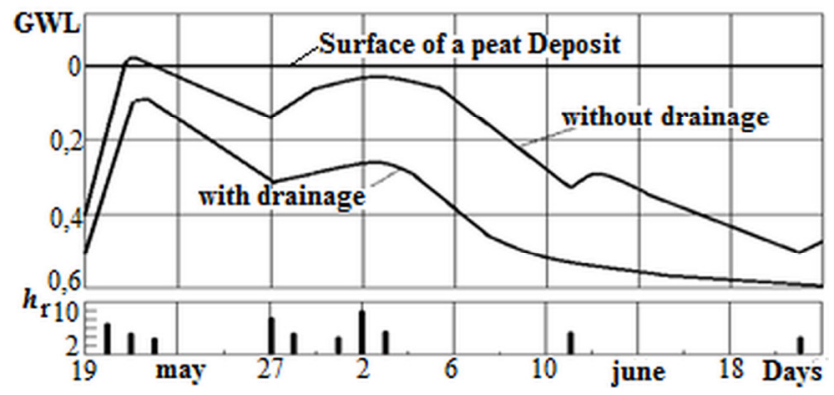

Fig. 3. Fluctuations in the underground water level.

The decrease in the underground water level caused by the action of drains directly affects the overlying zone providing it with the necessary water and air regime. The draining capacity $[19,20]$ of the deposit layer under study, expressed by the potential of moisture, as well as its moisture content change over time under the action of a drainage system, meteorological conditions, and deposit properties (Fig. 4).

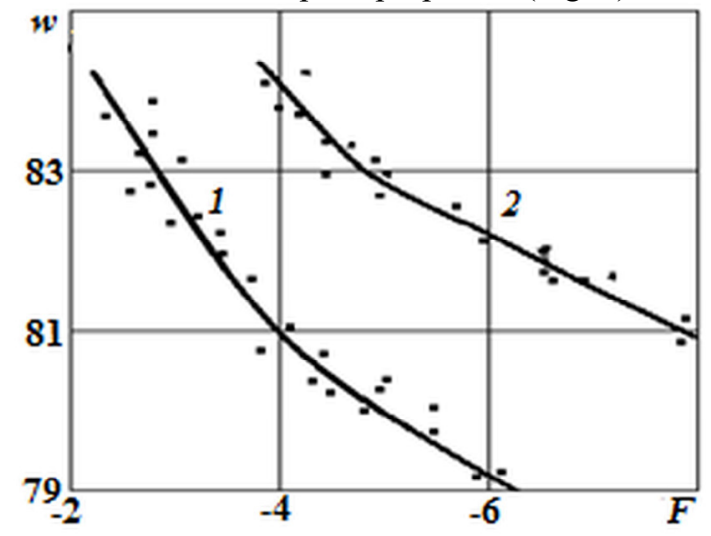

Fig. 4. The dependence of the milled peat moisture content on the potential for high-moor peat with a $15 \%$ degree of decomposition on the fields: 1 - No. $1 ; 2$ - No. 2 .

The processes of moisture movement at a peat deposit allow us to evaluate and justify measures to improve its water-air regime, which is used to develop intensive methods of draining a peat deposit and maintain the necessary water regime in it.

The moisture movement in the zone below the underground water level can be considered, to a first approximation, as a steady stationary flow. An important distinctive feature of the zone located below the underground water level is the capability of any cavity to pass water through with little resistance. If it is practically difficult to increase the effective water conductivity of a peat deposit, this can be achieved theoretically with a 
sufficiently frequent drainage to control the underground water level promptly. Drainage reduces the moisture content of the surface layer of a peat deposit.

Table 1. The moisture content of a surface layer of a high-moor peat deposit.

\begin{tabular}{|l|c|c|}
\hline \multirow{2}{*}{ Type of drainage } & \multicolumn{2}{|c|}{ Moisture content, \% } \\
\cline { 2 - 3 } & Field No.1 & Field No.2 \\
\hline Open drainage network & 84.1 & 84.2 \\
\hline Open drainage network with drains & 81.8 & 79.3 \\
\hline
\end{tabular}

According to the Table, the moisture content decreases by 3-4\% compared to the moisture content when the drainage network is open. After a peat deposit is milled, fragmented peat is dried beginning with a lower moisture content, with the drying time to the harvesting moisture content and, thereby, the duration of the cycle being reduced.

The density of the moisture flow can be reduced by increasing the surface runoff and moisture evaporation from the surface of a peat deposit (or from the top layer). In the aerated zone, any sufficiently large voids (drains) do not have a positive effect on the moisture conductivity of peat, since they are usually filled with air and do not contribute to the movement of moisture. Therefore, the use of both vertical and horizontal drainage in the zone above the underground water level is not able to improve the water regime of peat.

\section{Discussion}

The underground water level is directly determined by deposit properties and boundary conditions: the rate of incoming infiltration moisture, the design and location of drains, and hydrogeological conditions. The decrease in the underground water level caused by the action of drains directly affects the overlying zone maintaining the necessary water and air regime in it.

The magnitude and rate of the underground water level decrease determine the intensity of physical, chemical and microbiological processes occurring at a peat deposit - both in the aerated zone and in the zone below the underground water level. When peat is milled with a significant underground water level decrease of more than a meter, the dependence of technological operations on precipitation decreases.

An important distinction of the zone located below the underground water level is the capability of any cavity to pass through water with little resistance. If it is practically difficult to increase the effective moisture conductivity of a peat deposit, this can be achieved theoretically by sufficiently frequent drainage to control the underground water level on-the-fly.

It is actually more significant to maintain the water-air regime in the zone above the underground water level where peat is usually a three-phase system. This (aerated) zone can also include the places without any effective underground water level and any free underground water. The zone has a direct interaction with the supporting surfaces of peat machines and can be considered as a part of the technological process. The root layer is usually located in this zone.

\section{Conclusion}

To regulate the water regime of a deposit, functional control of technological processes in milling fragmented peat must be carried out with drainage which reduces the initial moisture content of dried fragmented peat and, thus, makes it possible to use favourable weather conditions to dry peat and change the depth of milling.

The system of open drains at a peat deposit consists of canals diverting water into 
outfall drains (main, gross ones and drains regulating surface runoff and underground water level - field drains (perpendicular to the gross drains), closed drains (diverting water from field drains into gross ones), and an interception fire drain.

The density of the moisture flow moving through a peat deposit to the underground water level and drains can be reduced by increasing the surface runoff and moisture evaporation from the peat deposit surface (or from the top layer due to water evaporation by plants). The moisture content can be changed at a constant moisture potential with the use of irreversible peat properties. Therefore, in order to improve a peat deposit drainability, which is necessary to mine peat by milling at a peat deposit, the following actions have to be taken:

- mechanical actions, such as structure destruction, peat compaction and its mechanical processing;

- temporary deposit overdrying or freezing, which can be considered as a type of peat dewatering;

- field surface profiling in order to create a flat surface with a slope towards drains;

- use of time-dependent effect to reduce the moisture content at a constant degree of draining;

- provision of a non-waterconducting top layer of a peat deposit by the intensive mechanical processing of this layer and the subsequent rolling of the surface;

- increase in evaporation from the peat deposit surface since peat milling makes the peat layer being dried a moisture isolator delaying the penetration of solar and scattered radiation into deposit underlying layers.

Taking into account the dynamics of peat property changes during draining allows us to adjust some parameters (the distance between drains, their depth, the use of equipment with less trafficability as the strength properties increase) and, thus, design a flexible process flow. At the same time, it is possible to consider weather factors, technical equipment and the total cost of a drainage network construction. The calculation of the drainage flowsheet at the design stage will determine the lead time, the volume and cost of earthwork.

\section{References}

1. B. F. Zyuzin, O. Misnikov, V. V. Panov, L. V. Kopenkina, Gornyi Zhurnal, 5, 73-76 (2013)

2. O. Misnikov, Mires and Peat, 21, 7, 1-14 (2018)

3. E. A. Kremcheev, A. S. Danilov, Yu. D. Smirnov, Journal of Mining Institute, 235, 96105 (2016)

4. O. Misnikov, Mires and Peat, 18, 22, 1-15 (2016)

5. O. S. Misnikov, I. O. Korolev, Polymer Science. Series D, 10:3, 255-259, (2017)

6. O. S. Misnikov, A. E. Afanas'iev, Theoretical Foundations of Chemical Engineering, 37, 6, 582-589 (2003)

7. O. S. Misnikov, E. Yu. Chertkova, Eurasian Mining. Gornyi Zhurnal, 1:21, 63-68 (2014)

8. O. Misnikov, V. Ivanov, E3S Web Conf., 15, 01017 (2017)

9. O. S. Misnikov, O. V. Dmitriev, E. Yu. Chertkova, Eurasian Mining. Gornyi Zhurnal, 2:24, 30-34 (2015)

10. O. Misnikov, E3S Web Conf., 21, 01020 (2017)

11. O. Misnikov, Polymer Science. Series D, 7:3, 252-259 (2014)

12. S. N. Gamayunov, O.S. Misnikov, Inzhenerno-Fizicheskii Zhurnal (IFZh), 71:2, 233234 (1998) 
13. O. S. Misnikov, O. V. Dmitriev, V. I. Popov, E.Yu. Chertkova, Polymer Science. Series D, 9:1, 133-139 (2016)

14. V. Lebedev, O. Puhova, E3S Web Conf., 105, 01006 (2019)

15. O. Misnikov, A. Timofeev, O. Pukhova, Polymer Science. Series D, 8:1, 66-7 (2015)

16. E. A. Kremcheev, D. A. Kremcheeva, Journal of Industrial Pollution Control, 33:1, 787-791 (2017)

17. E. A. Kremcheev, D. A. Kremcheeva, Indian Journal of Science and Technology, 9:12, 89525 (2016)

18. E. A. Kremcheev, D. O. Nagornov, Ecology, Environment and Conservation, 23:2, 956-965 (2017)

19. E. A. Kremcheev, D. A. Kremcheeva, Research Journal of Pharmaceutical, Biological and Chemical Sciences, 7:3, 1284-1289 (2016)

20. O. S. Misnikov Journal of Physics: Conference Series "International Conference «Complex equipment of quality control laboratories”, 1384, 012031 (2019) 